\title{
In the new coronavirus, current effects and precautions
}

\begin{abstract}
In China, the pathogen of the new coronavirus Covid-19 (coronavirus disease 2019; SARSCoV-2; previously called 2019-nCoV), originating from Wuhan and currently spreading over 6 continents, including 66 countries, is now a worldwide there are epidemics and these numbers are increasing rapidly. Countries are under increasing pressure to stop the spread of a global epidemic. At this stage, preparedness and correct sharing of information is essential to risk. This short article summarizes the current effects and measures of this new type of coronavirus.
\end{abstract}

Keywords: coronavirus, SARS-CoV-2, CoVID-19, epidemiology, features, strategies
Volume 4 Issue 2 - 2020

\author{
Ferhan Soyuer \\ Department of Physiotherapy and Rehabilitation, Faculty of \\ Health Sciences, Nuh Naci Yazgan University, Turkey
}

Correspondence: Ferhan Soyuer, Head of Physiotherapy and Rehabilitation Department, Faculty of Health Sciences, Nuh Naci Yazgan University, Turkey, Tel 05422354062, Email soyuerferhan@gmail.com

Received: March 22, 2020 | Published: April 24, 2020

\section{Introduction}

Coronavirus disease 2019 (COVID-19) is a disease caused by severe acute respiratory syndrome coronavirus 2 (SARS-CoV-2), first detected in China city Wuhan in December, 2019. The new coronavirus hasquickly spread to all Chinese states and 66 other countries as of March, 2020. ${ }^{1,2}$ It started out as the "Wuhan virus", everyone from the researchers to the news sources, including those in China - speaks this way. Then it was "Wuhan coronavirus" and "Chinese coronavirus" followed by 2019-nCoV. Finally, on February 11, the World Health Organization (WHO) gave the disease an official name: Covid-19., ${ }^{1,2}$

What is the difference between SARS Coronavirus 2 (SARS-CoV-2) and COVID-19?

SARS-CoV-2 is the name of the virus that causes COVID-19 disease. COVID-19 is short for Coronavirus Disease 2019. The "SARS" part of the name refers to the genetic linkage of the new coronavirus to the virus that caused the 2003 SARS epidemic. Efforts to retain the virus are ongoing; however, given the many uncertainties associated with pathogen contamination and virulence, the effectiveness of these efforts is unknown.As countries struggle with increasing numbers of cases and overcome the emergency rooms, there is a fierce struggle to manage the pandemic. ${ }^{1-3}$

\section{Mortality}

The epidemics in the Republic of Korea, Italy, Iran and Japan have been became the greatest concern of WHO. According to the European Centre for Disease Prevention and Control (ECDC), the latest daily risk assessment on COVID-19, March, they ECDC have now considered the risk moderate to high level. The Republic of Korea is known to provide treatment with adequate health facilities. As of March 20, it reported 86 deaths in 8360 cases, and the death rate was $1.1 \%$. The death rate in China is generally $2.1-3 \%$. Men make up $2 / 3$ of the deaths. $80 \%$ of deaths are over 60 years old. The youngest patient is a 1 month old newborn, and the oldest is over 90 . 6557 new cases and 793 new deaths in Italy (March 21). Italy now has the highest number of coronavirus deaths in the world, surpassing China. $^{3-5}$

\section{Symptoms}

Signs and symptoms of COVID-19 may appear two to 14 days after exposure and can include: Fever, cough, shortness of breath or difficulty breathing. Other symptoms can include: tiredness, cches, runny nose, sore throat. The severity of COVID-19 symptoms can range from very mild to severe. Some people have no symptoms. People who are older or have existing chronic medical conditions, such as heart or lung disease or diabetes, may be at higher risk of serious illness. ${ }^{4-6}$

\section{Causes and risk factors}

It's unclear exactly how contagious the new coronavirus is. It appears to spread from person to person among those in close contact. It may be spread by respiratory droplets released when someone with the virus coughs or sneezes. It may also be spread if a person touches a surface with the virus on it and then touches his or her mouth, nose or eyes. Risk factors for COVID-19 appear to include:Close contact with someone who has COVID-19 - such as when a family member or health care worker takes care of an infected person..$^{1,3,5}$

\section{Treatments and precautions}

Currently, there is no vaccine or antiviral therapy for human and animal coronavirus. Thus, identifying drug treatment options as soon as possible is critical for responding to the CoVID-19 outbreak. WHO announced that a vaccine for SARS-CoV-2 should be available within 18 months, but to achieve this, funding and public benefit will be provided even if the threat level drops. The protective measures to prevent the spread of SARS-CoV-2 coronavirus are the same as in any respiratory ailment. ${ }^{6,7}$ The basis of clinical management is largely symptomatic therapy and there is support in intensive care for serious patients. General strategies include bed rest and antiviral therapy, antibiotic administration, immunomodulatory therapy, organ function support, respiratory support, bronchoalveolar lavage, blood purification and extracorporeal membrane oxygenation. Although there is no vaccine available to prevent infection with the new coronavirus, you can take steps to reduce your risk of infection. ${ }^{7,8}$

WHO and CDC recommend following these precautions for avoiding COVID-19: ${ }^{1,2}$

I. Avoid large events and mass gatherings.

II. Avoid close contact (about 1 meter) with anyone who is sick or has symptoms.

III. Wash your hands often with soap and water for at least 20 
seconds, or use hand sanitizer that contains at least $70 \%$ alcoholic solutions.

IV. Cover your mouth and nose with your elbow or a tissue when you cough or sneeze.

V. Avoid touching your eyes, nose and mouth if your hands aren't clean.

VI. Clean and disinfect surfaces you often touch on a daily basis.

VII. Avoiding work, school, public transport, entering public areas if you are sick, staying at home

VIII. If you have a chronic medical condition and may have a higher risk of serious illness, check with your doctor about other ways to protect yourself.

\section{Conclusion}

Currently, little is known about CoVID-19, but it is known to be highly pathogenic, possibly a zoonotic agent. To deal with a rapidly spreading epidemic, the source of the virus, patagonosis should be determined? And how soon can it spread to the world? How does it affect groups among individuals and the elderly, such as those with chronic health problems? An outbreak has occurred. Steps to take are very important to stop the outbreak and save lives.

\section{Acknowledgments}

None.

\section{Conflcits of interst}

The author declares there is no conflct of interest.

\section{Funding}

None.

\section{References}

1. WHO. WHO Director-General's opening remarks at the media briefing on COVID-19 - March2020. 2020.

2. European-Centre-for-Disease-Prevention-and-Control. Daily risk assessment on COVID-19. 2020.

3. Drosten C, Günther S, Preiser W. Identification of a novel coronavirus in patients with severe acute respiratory syndrome. $N$ Engl $\mathrm{J}$ Med. 2020;348(20):1967-1976.

4. Guan WJ, Ni ZY, Hu Y, et al. Clinical characteristics of coronavirus disease 2019 in China. NEngl J Med. 2020.

5. Chaolin H, Yeming W, Xingwang L, et al. Clinical features of patients infected with 2019 novel coronavirus in Wuhan, China. The Lancet. 2020;395(10223):497-506.

6. Zumla A, Hui DS, Azhar EI, et al. Reducing mortality from 2019-nCoV:host-directed therapies should be an option. The Lancet. 2020;395(10224):e35-e36.

7. Burki T. Outbreak of coronavirus disease 2019. The Lancet Infectious Diseases. 2020;S1473-3099:30076-1.

8. Tang B, Wang X, Li Q, et al. Estimation of the transmission risk of the 2019-ncov and its implication for public health interventions. J Clin Med. 2020;9(2):1-13. 